\title{
O luto no processo de aborto provocado*
}

\author{
Loss and grief of women who had an abortion
}

El duelo en el proceso del aborto provocado

\section{Solange Maria dos Anjos Gesteira1, Vera Lúcia Barbosa², Paulo César Endo ${ }^{3}$}

\section{RESUMO}

Apresenta-se um relato da experiência a respeito da perda e do luto em mulheres que provocaram aborto. Buscamos, nessa abordagem e discussão, elementos para compreender esse processo. O abortamento provocado, ao longo do tempo, tem estado revestido de tabus e preconceitos que concorrem para que a assistência de enfermagem esteja centrada apenas nos procedimentos técnicos. Com isso, as mulheres em processo de abortamento provocado, que sofreram uma perda, ficam relegadas ao segundo plano, e necessário se faz que oportunidades sejam criadas para que elas vivenciem o seu luto. A enfermeira poderá, sobremaneira, ajudá-las nesse momento. A necessidade e a importância da abordagem sobre perda e luto no abortamento provocado decorrem da ausência de referência ao tema. Ao trazer à luz o sofrimento vivido por essas mulheres, espera-se que os elementos tornados visíveis sirvam como instrumentos de reflexão sobre o desempenho profissional e contribua, conseqüentemente, para a melhoria da qualidade da assistência de enfermagem prestada.

Descritores: Aborto; Aborto induzido/psicologia; Atitude frente à morte

\begin{abstract}
To describe the feeling of loss and grief of women who had an abortion. This conceptual served for this qualitative study. Discussion technique was the main approach to explore and comprehend women's experiences with the loss and the abortion process. Because abortion has been regarded for many years as taboo, this prejudice causes nursing care to be focused on the technical aspect of care only. Although nurses might be prepared to assist women who had an abortion, little opportunity is given to those women to express their loss and grief. Focusing attention on this problem may stimulate nurses to reflect upon the need of women who had experienced loss and abortion, which in turn may lead to better nursing quality care.
\end{abstract}

Keywoeds: Abortion; Abortion, induced/psychology; Attitude to death

\section{RESUMEN}

Se presenta un relato de experiencia, respecto a la vivencia de la pérdida y del duelo en mujeres que se provocaron un aborto. Buscamos, en ese abordaje y discusión, elementos para comprender ese proceso. El aborto provocado, a lo largo del tiempo, ha estado revestido de tabúes y prejuicios que contribuyeron a que la asistencia de enfermería esté centrada sólo en los procedimientos técnicos. Con eso, las mujeres en proceso de aborto provocado, que sufrieron una pérdida, quedan relegadas a un segundo plano haciéndose necesario la creación de oportunidades para que ellas vivencien su duelo. La enfermera podrá, enormemente, ayudarlas en ese momento. La necesidad y la importancia del abordaje sobre la pérdida y el duelo en el aborto provocado surgen de la ausencia de referencias relacionadas al tema. Al traer a la luz el sufrimiento vivido por esas mujeres, se espera que los elementos tornados visibles sirvan como instrumentos de reflexión sobre el desempeño profesional y contribuya, consecuentemente, en la mejoría de la calidad de la asistencia prestada por la enfermería.

Descriptores: Aborto; Aborto inducido/psicologia; Actitud frente a la muerte

\footnotetext{
${ }^{1}$ Vivências originadas no transcurso da Disciplina "As Questões do Vinculo na Assistência da Criança e do Adolescente: Subsídios da Psicanálise, cursada em 2003".

${ }^{2}$ Professora Adjunto IV do Departamento de Enfermagem Comunitária da Escola de Enfermagem da Universidade Federal da Babia - UFBA - Salvador (BA), Brasil; Pesquisadora do Grupo de Estudos sobre Saúde da Mulher - GEM; Doutoranda do Programa de Pós Graduação em Enfermagem da Universidade Federal de São Paulo - UNIFESP - São Paulo (SP), Brasil.

${ }^{3}$ Professora Adjunto III do Departamento de Enfermagem da Universidade Federal de São Paulo - UNIFESP - São Paulo (SP), Brasil

${ }^{4}$ Professor Dr. em Psicologia do Desenvolvimento Humano. Recém Doutor do Centro Brasileiro de Análise e Planejamento - CEBRAP. Pesquisador do Núcleo de Psicanálise e Sociedade da Pontifícia Universidade Católica de São Paulo - PUC (SP), Brasil.
} 


\section{INTRODUÇÂO}

O abortamento provocado tem sido apontado por alguns autores como decorrência do desconhecimento da mulher dos métodos de se evitar uma gravidez, da falta de educação sexual e paternidade "irresponsável", acrescidos da escassez da tecnologia contraceptiva nos serviços básicos de saúde ${ }^{(1)}$. Diante desses aspectos, a mulher torna-se desesperançosa, como que fadada a enfrentar uma gravidez que não quer, ou não está em condições de levar adiante.

As mulheres têm apresentado uma gama de fatores que justificam a sua decisão de não prosseguir com a gravidez, tais como: condição financeira inadequada, violência doméstica, projeto de vida, desemprego e prole numerosa, dentre outros ${ }^{(2)}$. Quando se deparam com uma gravidez indesejada, as mulheres passam por um processo solitário, muitas vezes sem contar com o apoio do parceiro e/ou da família, recorrendo quase sempre a amigas que também já vivenciaram a mesma situação.

A mulher que não deseja a gravidez só vê como saída, a prática do aborto ${ }^{(3)}$. Do momento em que a gravidez é confirmada até a decisão final de interrompê-la, ela passa por um período complicado, em que fica extremamente sensível.

Ao abortar, a mulher com seqüelas da prática abortiva procura os serviços de saúde, e torna-se necessário que os profissionais de saúde, em especial as(os) enfermeiras(os), estejam sensibilizadas(os) com esta parcela da população feminina e com a sua problemática, não esquecendo que, além da assistência técnica, nesse momento, elas estão necessitando também de assistência com relação ao processo de perda e, conseqüentemente, à vivência do seu luto. Ao trazermos tais vivências, acreditamos estar contribuindo para o processo de sensibilização das(os) profissionais de saúde com relação a essa temática.

Os questionamentos com relação ao aborto provocado e o luto foram originados no transcurso da Disciplina "As questões do vínculo na assistência à criança e ao adolescente: subsídios da psicanálise", quando foram discutidos aspectos referentes ao sentimento de perda das mães, quando necessitam, por várias situações, afastarem-se dos seus filhos. Surgiram, então, questionamentos, resultando neste estudo que tem como objetivo trazer para discussão e reflexão a vivência da perda e do luto pelas mulheres em processo de aborto provocado.

\section{O ABORTO}

O aborto é definido como "a expulsão ou extração do feto que pese menos de $500 \mathrm{~g}$, com a idade gestacional aproximadamente em torno de 20-22 semanas completas, ou 140-154 dias completos"(4-5).

Geralmente, é considerado que antes de 20 semanas completas de gestação o feto não sobrevive, mesmo que sejam utilizados aparelhos artificiais. Poderá haver ou não viabilidade do feto com 20 a 27 semanas, e a sua condição de vitalidade estará presente, após 27 semanas completas de gestação $0^{(6)}$.

O aborto é considerado espontâneo quando da "interrupção natural da gravidez antes da 20 semanas de gestação" (7), e provocado, induzido ou inseguro, quando, para efetivá-lo, utiliza-se de qualquer processo abortivo externo, químico ou mecânico. Este último pode ter a participação voluntária ou involuntária da gestante, e ser considerado legal ou ilegal ${ }^{(4,8-9)}$.

O aborto não é isento de risco. As complicações resultantes dele são das mais diversas ordens, e a mulher nesta situação poderá apresentar ou não: hemorragia, infecção, perfuração uterina, laceração cervical, esterilidade, culpa, depressão e morte materna ${ }^{(5)}$.

Com relação ao aborto provocado, a estimativa da Organização Mundial da Saúde (OMS) é de que ocorra no mundo cerca de 70 mil mortes de mulheres devido a complicações secundárias a esse tipo de aborto. No Brasil, representa a quarta causa de morte materna, e é expressivo o quantitativo de internações em leitos hospitalares de ginecologia devido a complicações resultantes do aborto provocado $^{(10-11)}$. Pelas estimativas do DATASUS/MS, ocorrem no País de 1 a 1,2 milhões de abortamentos ao ano. Estes constituem a quinta causa de internação no Sistema Único de Saúde (SUS), e são responsáveis por $9,0 \%$ das mortes maternas e $25,0 \%$ das esterilidades por causa tubária ${ }^{(12)}$.

Observa-se, de modo geral, que os abortos provocados são realizados sob péssimas condições sanitárias, resultando em prejuízos à saúde das mulheres $^{(11)}$. O aborto provocado, no Brasil, constitui-se num problema de saúde pública, haja vista a sua alta incidência. Invariavelmente, resulta de uma gravidez indesejada, aproximando-se de dez milhões o número de mulheres expostas a esse tipo de gestação, seja por uso inadequado de métodos anticoncepcionais, por falta de conhecimento e ou acesso a eles, por insuficiente número de serviços para o atendimento, pelas condições sociais e econômicas desfavoráveis, pela baixa escolaridade familiar e pelo desemprego ${ }^{(12-13)}$.

O processo de abortar leva as mulheres a um dilema pois, para elas, essa é uma decisão muito difícil. As mulheres, quando decidem interromper a gravidez, encontram-se em conflito em virtude de suas crenças, princípios religiosos e valores, os quais contribuem para o aparecimento do sentimento de culpa. Quando decidem, sozinhas ou junto ao parceiro ou à família, as mulheres trabalham essa culpa, deixando-a em segundo plano, visando à resolução imediata de sua situação. Para 
elas, o aborto torna-se a sua única saída, o que servirá para amenizar o sentimento de culpa ${ }^{(3)}$.

O abortamento é um problema obstétrico comum e, muitas vezes, pode ser encarado pela equipe de enfermagem como rotineiro. Porém, para a mulher e para a família, independente da gravidez ser planejada ou não; essa perda sempre vem acompanhada do sentimento de culpa. Devido a isso ${ }^{(5)}$, muitas mulheres nessa situação passam por um processo de dor equivalente ao causado por outras perdas pessoais. $\mathrm{Na}$ vigência da perda de um filho por aborto, a assistência deve ser similar àquela prestada às mulheres que se encontrem no puerpério, e as(os) enfermeiras(os) devem prestar atenção acurada, com vistas à identificação de possíveis problemas quando da avaliação e estabelecimento do diagnóstico de enfermagem.

As(os) profissionais de enfermagem, devem estar atentas(os) para a identificação dos seguintes problemas ${ }^{(5)}$ : medo relacionado ao risco de perda da gestação; conhecimento deficiente em relação à causa do aborto; dor relacionada com as cólicas abdominais e com contrações da musculatura uterina; alteração da autoestima relacionada com os sentimentos de culpa pelo abortamento; risco de traumatismo relacionado com a retenção de tecido e a exigência de cirurgia para o esvaziamento uterino; estresse causado pelo nãocumprimento dos ritos religiosos fúnebres do casal e/ou da mulher; riscos de traumatismos relacionados com a possível isoimunização de uma mãe portadora de fator Rh negativo.

Concordamos com a autora supracitada, mas acreditamos ser necessário, além da atenção voltada para esses problemas, enfatizarmos o luto que está presente na vida dessas mulheres, e que devemos acrescentá-lo ao plano terapêutico, visando a melhoria da qualidade de vida dessas mulheres.

\section{O LUTO COMO COMPONENTE DO PLANO TERAPÊUTICO}

A idéia de morte está associada à idéia de perda ${ }^{(14)}$. Isto acontece porque nas relações afetivas são investidos amor, amizade, segurança, esperança, e a separação traz a dor psíquica de tristeza, de solidão, de medo e insegurança e de finitude ${ }^{(15)}$. Ante uma perda, não existe a possibilidade de trocas afetivas que foram prazerosas. Para essa dor, não há remédio que proporcione alívio imediato e, muitas vezes, ela pode ser geradora de dor física e criar uma dinâmica incompreensível para quem a vivencia e não a elabora ${ }^{(14)}$.

Após uma perda há o desenvolvimento de uma grande quantidade de emoções, experiências e mudanças na vida psíquica da pessoa, e o tempo de duração da vivência dessa perda dependerá da intensidade da relação com o objeto perdido ${ }^{(16)}$.

A perda de qualquer ordem gera o sentimento de luto ${ }^{(17)}$. Refere essa autora que, geralmente, quando falamos em luto, estamos nos referindo à morte de uma pessoa querida, mas, a aplicação do termo luto tem maior abrangência. O luto é uma reação normal e esperada quando um vínculo é rompido, e sua função é proporcionar a reconstrução de recursos e viabilizar um processo de adaptação às mudanças ocorridas em conseqüência das perdas. Existem fatores que determinam o processo do luto que são: os fatores internos; estrutura psíquica do enlutado; histórico de perdas anteriores; circunstâncias da perda; crenças culturais e religiosas e apoio recebido ${ }^{(18)}$.

A morte desperta, com freqüência, evocações de perdas ou separações do passado, e o sentimento de luto decorrente pode ser expresso por alguns sintomas tais como: depressão; ansiedade; culpa; raiva e hostilidade; falta de prazer; solidão; agitação; fadiga; desamparo; distúrbio de sono; perda de energias; queixas somáticas; aumento do uso de psicotrópicos, bebidas alcoólicas e fumo; aumento da suscetibilidade a doenças; lentidão de pensamento e concentração; mudança de hábito alimentar e dificuldade de manter relacionamentos ${ }^{(18)}$.

O processo de luto compõe-se das seguintes fases: de entorpecimento, que geralmente dura de algumas horas a uma semana e pode se interrompida por explosões de aflição e/ou raiva extremamente intensas; de anseio e busca da figura perdida, que dura de alguns meses, por vezes ano; da raiva e da urgência de recuperar a pessoa perdida; de desorganização e desespero e, finalmente, de reorganização ${ }^{(19)}$.

A expressão mais freqüente com relação a uma perda é o choro. Mas, muitas vezes as lágrimas decorrentes de uma perda são associadas à fraqueza e inadequação pessoal ${ }^{(20)}$. No entanto, chorar é uma maneira natural de aliviar a tensão interna e permite que seja comunicada a necessidade da pessoa de ser confortada. $\mathrm{Na}$ sociedade atual, há o encorajamento de muitas pessoas enlutadas a deixarem prematuramente a experiência do luto. Dessa conduta poderão ocorrer, como resultado, dois fatores: o enlutado vivencia seu luto isoladamente ou força-se a abandoná-lo antes de tê-lo completado. Existe ainda o empenho de familiares e amigos para que o enlutado desenvolva autocontrole, por entenderem ser essa a resposta adequada. Isto se torna difícil para o enlutado, pois deverá enfrentar essa mensagem poderosa que o encoraja à repressão emocional. É importante não mascarar ou fugir do luto porque esse comportamento poderá favorecer o aparecimento de problemas futuros. Do mesmo modo, a pessoa enlutada deve receber reconhecimento social para a sua dor pois, caso contrário, poderá temer que seus pensamentos e 
sentimentos sejam anormais, o que nem sempre ocorre ${ }^{(20)}$.

O luto não reconhecido e não resolvido constitui-se num dos principais fatores, não sendo percebido, muitas vezes, que nestes casos podem levar as pessoas a procurarem terapia por falta de motivação, por depressão, por doenças crônicas e ou por crises da meia idade ${ }^{(21)}$. Alguns aspectos presentes no cotidiano de hoje podem ser resultado ou estar relacionados a perdas não resolvidas do passado, das quais as pessoas não suspeitam da origem e, portanto, não sabem que estão diretamente envolvidas nos seus problemas.

No que tange à perda de um filho ${ }^{(22)}$, isto implica num tipo particular de luto, pois solicita adaptações, tanto sob os aspectos individuais, como na relação com o(a) esposo(a) no sistema familiar e na sociedade. O luto por um filho é marcado por muita culpa e revolta.

Em se tratando do aborto como causa de perda de um filho, ele é considerado como um não evento, pois não aconteceu o nascimento e nem houve a morte convencional ${ }^{(17)}$. Para essa autora, a mulher em situação de aborto vivencia o "luto não autorizado" que se refere às perdas "que não podem ser abertamente apresentadas, socialmente validadas ou publicamente pranteadas"(23).

Esse tipo de luto foi dividido em relacionamentos não reconhecidos, perdas não reconhecidas e enlutado não aceito como tal ${ }^{(23)}$. Nos relacionamentos não reconhecidos, temos como exemplo: vínculos extraconjugais, relacionamentos homossexuais, ex-cônjuge ou amantes, pais biológicos de crianças adotivas e médicos e enfermeiras que se vincularam aos pacientes. Nas perdas não reconhecidas podemos exemplificar: mortes perinatais, abortos, devolução de crianças adotadas aos pais biológicos, disponibilidade de filhos para adoção, morte de animal de estimação, perda social e psicológica sem morte, por exemplo, quando o parceiro desenvolve o mal de Alzheimer. Com relação ao enlutado não aceito como tal, podemos citar: crianças consideradas muito pequenas para estar de luto, ou adultos considerados muito velhos ou com alterações cerebrais, por exemplo, quando a morte ocorre num asilo, num hospital psiquiátrico ou em uma instituição para pessoas com dificuldades de aprendizagem.

Para as pessoas incluídas na classificação do "luto não autorizado", a manifestação desse luto poderá ser problemática, porque: ele pode ser intensificado por ter sido ignorado ou reprimido; a raiva e a culpa podem surgir e complicar o curso do processo de luto; o enlutado pode ser excluído dos rituais; falta apoio social para o enlutado vivenciar o processo do luto ${ }^{(24)}$.

Ao discutir sobre o "luto não autorizado" na categoria "perdas não reconhecidas", classificação em que está incluído o aborto provocado, Bromberg ${ }^{(17)}$ refere que este terá influência sobre a futura mãe, podendo a mulher apresentar um trauma psicológico e não engravidar novamente. Outro aspecto apontado pela autora é que o luto tem que ser vivenciado e as pessoas têm que elaborar as suas perdas, pois o luto poderá manifestarse não só na tristeza padrão, como também em doenças psiquiátricas. De acordo com essa autora, para que o luto seja superado, a dor não deve ser sublimada.

Estudos mostram que, para dissipar a dor psíquica de uma perda, é necessário que ela seja dita, vivida, sentida, refletida e elaborada, mas nunca negada. Outro aspecto que também ajuda no processo do luto são os rituais fúnebres, porque, a recuperação é centrada na aceitação, e o velório permite que as pessoas se despeçam e que o enlutado seja considerado como tal ${ }^{(25)}$.

Nesse contexto, o que observamos é que as mulheres em processo de abortamento provocado, vivenciam uma situação que tem o estigma da sociedade. E isso se reflete na nossa prática diária. Elas vivenciam a própria perdar e o luto sozinhas, pois, não raro, se hospitalizam e as famílias nem sequer têm conhecimento da sua situação. As pessoas que elas têm próximas são os profissionais de enfermagem que, muitas vezes, não se dão conta dessa necessidade em particular, sendo a assistência voltada especificamente para os cuidados técnicos. Essas mulheres estão fragilizadas, precisam de acolhimento, paciência e atenção. Elas podem estar desorganizadas, incoerentes, assustadas e paralisadas ${ }^{(18)}$. Acreditamos que o atuar dos profissionais de saúde e especificamente das enfermeiras deve estar pautado no sentimento de perda e luto que as mulheres estão vivenciando e não conseguem ou não podem expressar.

A postura que devemos ter perante uma mulher em processo de abortamento provocado não deve diferir da postura que temos ante uma pessoa enlutada, a saber: ter disponibilidade para escutar com atenção a mulher que está sofrendo, sem julgá-la ou criticá-la; deixá-la falar, mostrando que a está ouvindo, não precisando concordar com o ponto de vista dela, mas escutá-la e identificar o que está dizendo; manter-se em silêncio ou próxima a essa mulher são formas de ajuda não verbal; a escolher um ambiente agradável, confortável, sem barulhos constantes e passagens de outras pessoas, é acolhedor, e a enlutada percebe que é respeitada; quando for preciso, dar-lhe más notícias, (a)o profissional deve sentar-se e fornecer-lhe informações claras e precisas, avaliando a quantidade destas que ela pode absorver ${ }^{(18)}$.

Por outro lado, para que esse atendimento seja diferenciado, deve haver um investimento nos profissionais de saúde, no sentido de trabalhar as perdas, pois ${ }^{(26)}$ esses profissionais estão sujeitos a experiências de perdas no seu cotidiano profissional e são poucos os cursos que preparam seus graduandos para o contato com o processo de morte de uma pessoa. Ainda existe uma exposição dos profissionais de saúde a um tipo de desgaste intenso e, assim, podem apresentar dificuldades 
ao enfrentarem a finitude do paciente. $\mathrm{E}$, no que se refere à mulher em processo de abortamento provocado, existe uma implicação maior pelas múltiplas facetas que envolvem o problema.

\section{CONSIDERAÇÕES FINAIS}

Ao relatarmos a vivência do luto por mulheres em processo de abortamento provocado, buscamos visibilizar um aspecto que ainda não é reconhecido como parte significativa do cuidado de enfermagem. Em primeiro lugar, queremos chamar a atenção das enfermeiras que atuam nas unidades de ginecologia e obstetrícia, para que fiquem atentas aos fatos e, inicialmente alicerçadas na observação, disponham-se a discutir essa temática e criem meios para torná-la inerente ao cuidado de enfermagem. Quando atentamos para os fatos, temos a oportunidade de presenciar cenas reveladoras sobre a vivência do luto, como a verbalização de uma cliente em situação de aborto provocado:

"Eu não queria perder meu filho, fiquei com raiva de mim por ter tomado, e do meu marido por ter comprado o remédio".

Sabemos que criar espaço para discutir a vivência do luto é um passo importante, que necessita ser verbalizado e trabalhado, tanto com as mulheres em processo de abortamento provocado quanto com a equipe de assistência, especialmente com as enfermeiras que não foram preparadas durante sua formação para abordagem desse aspecto na prestação da assistência a essa parcela da população.

A fundamentação obtida nos estudos sobre as questões do luto nos fez refletir sobre a importância que esse conhecimento proporciona, instrumentalizando o fazer da enfermagem no que concerne às situações psíquicas que envolvem o cliente e seu cuidador.

\section{REFERÊNCIAS}

1. Schor N, Alvarenga AT. O aborto: um resgate histórico e outros dados. Rev Bras Crescimento Desenvolv Hum. 1994; 4(2): 12-7.

2. Gesteira SMA. Assistência prestada à mulher em processo de aborto provocado: o discurso das mulheres e das profissionais de saúde [tese]. São Paulo: Universidade Federal de São Paulo.Departamento de Enfermagem; 2006.

3. Oliveira EM, Vianna LAC, Schirmer J, Scavone L, Fonseca RMGS, Tavares MSG. A mulher e o aborto: da decisão à prática [relatório de pesquisa] São Paulo: 1998261 p.

4. Neme B. Abortamento séptico. In: Neme B. Obstetrícia básica. São Paulo: Sarvier; 1994. p.890-7.

5. Burroughs A. Uma introdução à enfermagem materna. Traduzido por Thorell AMV. 6a ed. Porto Alegre: Artes Médicas; 1995. p.339-41; 376-9.
6. Epner JEG, Jonas HS, Sekinger DL. Aborto tardio. JAMA Brasil 1999; 3(4): 889-904.

7. Salomão AJ. Abortamento espontâneo. In: Neme B. Obstetrícia básica. São Paulo: Sarvier; 1994. p.363-70.

8. Rede Nacional Feminista de Saúde e Direitos Reprodutivos (REDESAÚDE). Dossiê - Mortalidade Materna [texto na internet]. São Paulo; 2001. [citado 2002 Mai 14]. Disponível em: http://www.redesaude.org.br/rede/admin/ publicacoes/113.pdf

9. Resende J. Abortamento provocado. In: Resende J. Obstetrícia. 8a ed. Rio de Janeiro: Guanabara Koogan; 2000, p. 1401-15.

10. Rede Nacional Feminista de Saúde e Direitos Reprodutivos (REDESAÚDE). Cartilha saúde materna: componente essencial dos direitos reprodutivos [texto na internet]. São Paulo; 1998. [citado 2004 Fev 26]. Disponível em: http:// www.redesaude.org.br/rede/admin/publicacoes/

11. Costa SH. Aborto provocado: a dimensão do problema e a transformação da prática. In: Giffin $\mathrm{K}$, Costa SH ,organizadoras. Questões da saúde reprodutiva. Rio de Janeiro: Editora Fiocruz; 1999. p.163-84.

12. Brasil. Ministério da Saúde. DATASUS/SE/MS. Saúde da mulher [texto na Internet]. Brasília: Ministério da Saúde; 1993; [citado 1999 Nov 13]. Disponível em http:// http:// www.saude.gov.br

13. Brasil. Ministério da Saúde. Notícias de 28 de maio de 2003 [texto na Internet]. Brasília: Ministério da Saúde; 2003, [citado 2003 Jun 25]. Disponível em: http://portal.saude.gov.br/ saude/

14. Grutapas - Tanatologia. A dor da morte [texto na internet]. São Paulo; 2004. [citado 2004 Out 15]. Disponível em: h t t p : / / ww w.obito.com.br/psicologia / psicologia2.asp?id=219

15. Ballone GJ. Lidando com a morte [texto na internet]. In: Psiqweb: Psquiatria geral. São Paulo; c2002. [citado 2004 Out 15]. Disponível em: http:/ /gballone.sites.uol.com.br/ voce/morte1.html

16. Ballone G. J. Lidando com a perda (para a família) [texto na internet]. In: Psiqweb: Psuiatria oncológica. São Paulo; c2002 . [citado 2004 Out 15]. Disponível em: http:// gballone.sites.uol.com.br/psicossomatica/cancer3.html

17. Bromberg MH. Morte não é castigo [entrevista] Revista Isto É. 1999. Abr no 1541.

18. Bromberg MHPF. O processo do luto. Rev Hands [peródico na Internet]. 2000 [citado 2004 Out 15];1(outubro/novembro):[cerca de 3 p]. Disponível em: http://www.daycare.com.br/materia.asp?id=40

19. Bowlby J. Apego e perda: perda: tristeza e depressão. $3^{\mathrm{a}}$ ed. São Paulo: Martins Fontes; 1998. v.3.

20. Bromberg MHP, Kovács MJ, Carvalho MMMJ, Carvalho VA. Vida e morte: laços de existência. São Paulo: Casa do Psicólogo; 1996.

21. Andreas C, Andreas S. Heart of the mind. Moab, Utah: Real People Press; 1989.

22. Instituto 4 Estações. A dor de perder um filho é para sempre? [texto na internet]. São Paulo; 2004. [citado 2004 Out 15]. Disponível em: http://www.obito.com.br/ global/Imprimir.asp?id=43

23. Doka K. Disenfranchised grief: recognizing hidden sorrow. Lexington, MA: Lexington Books; 1989.

24. Parkes CM. Luto: estudos sobre a perda na vida adulta. Trad. 
de Maria Helena Franco Bromberg. São Paulo: Summus; 1998. (Coleção novas buscas em psicoterapia, 56).

25. Queiroz R. Dossiê luto - A vida de quem fica. Revista Marie Claire [ periódico na Internet]. São Paulo: Editora Globo S.A. 2002. [citado 2004 Out 15]. Disponível em: http:// marieclaire.globo.com/idic/ed103/rep_luto1.htm 26. Oliveira CC. Profissionais cuidando de si. [texto na internet]. São Paulo; 2004. [citado 2004 Out 15]. Disponível em: http://www.obito.com.br/global/Imprimir .asp?id=394 